\title{
An Analytical-Comparative Investigation of the Migration Flows in Informal Settlements of Karganeh, Ali Abad and Gel Sefid of Khorramabad City, Lorestan Province $^{1}$
}

\author{
Mohammad Fathi Beyranvand \\ $\mathrm{Ph}$. D student of geography and urban planning, Scince and research Branch \\ Islamic Azad University, Tehran, Iran. \\ Tel: 98-916-161-3246Ｅ-mail: fathi4070@yahoo.com
}

Asghar Nazarian (Corresponding author)

Professor of geography and urban planning, Scince and research Branch

Islamic Azad University, Tehran, Iran.

\section{Kazem Jajarmi, Ezat Olla Ezati}

Professor of geography and urban planning, Scince and research Branch

Islamic Azad University, Tehran, Iran.

Received: July 22, 2014 Accepted: August 5, 2014

doi:10.5296/emsd.v3i2.6006 URL: http://dx.doi.org/10.5296/emsd.v3i2.6006

\begin{abstract}
Undoubtedly, the formation of informal settlements in Khorramabad in a certain line with other informal settlements are influenced by the presence and establishment of an uneven flow of immigration to this city in order that hereby non-affluent immigrants in the vacuum and inability of the formal market in providing their housing, propose a solution, even simple, for providing a minimal shelter where guarantees their life and settlement needs in some part of the city. For now, 212 Hectares of the total area of 3885 hectares of Khorramabad, with a

\footnotetext{
${ }^{1}$ The present article has been extracted from the Mohammad Fathi's PhD Dissertation titled as "Investigating the Space of Conceptual and Functional Flows and Approaches in Informal Settlements".
} 
population of 47 thousands individuals, are available in the form of 11 informal settlements in Khorramabad city.

The present study is an applied one and the method employed in it is descriptive-analytical. The main objective of the present study is to investigate and analyze the immigration flows in the informal settlements of Khorramabad city. The results obtained from the study indicate that the proportion of rural repulsions is more than urban attractions in the formation of rural immigrations to the informal settlement regions of Khorramabad. In addition, a sensitive tendency is present among the residents of these regions to immigrate to the center of the city and other big cities and metropolises.

Keywords: Informal settlements, Immigration, Flow, Khorramabad City

\section{Introduction}

Nowadays, the displacement and formation of immigration flows, particularly in developing countries, are among the issues which not only encounter the construction and development of villages as the canons of agricultural products and providers of food form urban settlers with a serious challenge, but they also have had unfavorable outcomes and urban chaos such as informal settlements and the population explosion phenomenon in big cities.

In all the Third World countries, immigration has been always taken place form the less-developed regions to the developed ones in which more investments are made and there are more opportunities regarding the issue of employment and income for immigrants (Shokuee, 2010: 171). In the formation of informal settlements, the proportion of villagers; immigrations is significantly more than other kinds of migrations.

For now, 212 hectares of the total of 3885 hectares-area of Khorramabad welcomes the a 47 thousand individual population of poor citizens who are influenced by the phenomenon of immigration in the form of 11 informal settlements have constructed uneven and heterogeneous neighborhoods as a part of the continuous structure of the city. These neighborhoods, in addition to establishing different kinds of flows with surrounding spaces which are required for its survival, have recognized its presence as an inseparable part of in the geographical space of the city and imposed itself to the structure of the city. Surely, presenting any kind of reformist solution for the reformation of the physical, functional, economic and social structures of these settlements and also preventing form the expansion and managing this phenomenon in cities of Iran require a comprehensive knowledge of different immigration flows including flows that are the factors of this phenomenon or other flows which may result in the displacement of the residents of these settlements in the continuous network within the country. Lack of attention to the factors and effects of these two kinds of flows can result in the formation of population explosion in some big cities or the occurrence of the phenomenon of gradual depletion of the population in some small cities and villages.

Accordingly, in the present study, it is tried to first investigate the motivational factors effective on the occurrence of immigration phenomenon which itself is the reason of the formation of informal settlements and in the next step, the possibilities related to the displacement and immigration of the residents of informal settlements in the urban network of Iran will be 
investigated.

\section{Immigration and Marginalization}

Marginalization, both in the millennium objectives and in the United Nations Human Settlements is introduced as one of the challenges of the development of the world (UN, 2003: 2000). The researchers have investigated the reasons of the marginalization and in general the issue of migration in the framework of the push-pull model and described the factors such as poverty and the lack of welfare-health facilities and the most important one, the issue of employment and more income in cities (Varesi, 2006). Some researches which have been conducted in the fields of the ethnic and population structures and the primary origins of the marginalized indicate that approximately one fourth of the marginalized are rural immigrants (Samavati, 1993: 167), which due to the rural push factors with the principles of social, economic and cultural urban life has different population, behavioral, ethnic and psychological outcomes (Jamali, 2002: 1).

Knowing the reasons of the advent and expansion of marginalization require the study of rural immigrations, but what comes as follows is a brief overview of this phenomenon and tries to indicate the close relationship of these two phenomena (immigration and marginalization). The advent of the issue of marginalization is not only due to the issue of immigration and sometimes the expansion of cities has changed some of the surrounding villages as the marginalized regions and sometimes there are immigrations, but they will not result in marginalization (Zahed Zahedani, 1990: 17).

Immigration is a mechanism which sometimes causes marginalization, but it is not the ultimate reason for marginalization. However, there has been no official statistics which be based on the national studies, based on estimations, at least $10 \%$ and maximum $50 \%$ (with the mean of 20\%) of the residents of cities of the centers of Iran's provinces and a population more than 10 to 12 million people live in marginalized regions (Naghdi, 2003: 228). The majority of the marginalized originate from rural regions and during the flow of cities' development, they have migrated from their birthplaces and have come to the poles of urban development and resided in thickets and sheds (Haj Yusofi, 2003).

Recent studies indicate that a high proportion of the marginalized regions particularly in big cities, are low income groups of these cities which because of the increase in economic life which is difficult in big cities, they resort to cheaper regions (Eftekhari Rad, 2003: 74).

\section{Motivational Factors Effective on the Formation of the Phenomenon of Migration to Khorramabad City}

The main reasons of immigration in different regions of the world is different on the immigration continuum of city - village. The motivational factors effective on the formation of this phenomenon is mainly divided into two main groups: factors "urban attraction" and factors "rural repulsion". In different geographical points in the world, one or a set of these factors are effective on the decisions of the immigrants to migration and displacement from one point to another. For example, the results of the researchers' studies indicate the more influencing of the role of the urban pull factors in the regions of western Asia and Latin America and the more 
influencing of the factor of rural push in regions of the southern Asia and Africa in formation of the phenomenon of immigration (Gizewsky \& Thomas, 1995).

To determine the role of each of these factors in immigrants' making decisions among the rural immigrants residing in the triple studied informal settlements and also being aware of the issue whether principally, the occurrence of immigration among the residents of each three neighborhood have shared factors and origins or it originates from different factors or reasons, attentive studies and evaluations have been conducted, whose results will be discussed.

\subsection{Urban Life Attractions}

The possibility of further education and taking higher scientific degrees for family members, having a prosperous and ideal life with enjoying all aspects of urban life, the possibility of finding an appropriate job with appropriate income for oneself and other family members, civil liberties particularly regarding making friends and the selection of the type of dress and desired clothes, anonymity and fleeing form annoying and boring constraints due to the views of relatives and rural residents are among the pulls of urban life which can engender required motivation for a large part of rural immigrations.

The following table indicates the factors of "urban attractions" as a part of the motivational factors among the rural immigrants residing in every studied informal settlements.

\begin{tabular}{|l|l|l|l|}
\hline The studied group of motivational factors in & Karganeh & Ali Abad & Gel Sefid \\
\hline Factors of urban attractions & 41.3 & 47.2 & 40.8 \\
\hline
\end{tabular}

Among the group of the factors of "urban attractions", the proportion of each of the main motivations of the rural immigrants residing in the studied neighborhoods for migrating to Khorramabad are as follows:

\begin{tabular}{|l|l|l|l|}
\hline $\begin{array}{l}\text { The main motivation of the villagers residing in the triple neighborhoods for } \\
\text { migrating }\end{array}$ & Kerganeh & $\begin{array}{l}\text { Ali } \\
\text { Abad }\end{array}$ & $\begin{array}{l}\text { Gel } \\
\text { Sefid }\end{array}$ \\
\hline Seeking better job and higher income & 54.2 & 60.1 & 67.7 \\
\hline Further education & 21 & 13 & 11.1 \\
\hline Promoting the welfare level and using the benefit of urban facilities & 17.3 & 12.3 & 12.5 \\
\hline Civil liberties &.$/ 7$ & 2.9 & 4 \\
\hline Other & 6.8 & 11.7 & 4.7 \\
\hline Total & 100 & 100 & 100 \\
\hline
\end{tabular}

The complementary studies surrounding the determination of the promotion of each of the main factors in the selection of studied settlements as the desired alternative of the rural immigrants of Khorramabad for residing and living in these neighborhood are as follows:

\begin{tabular}{|l|l|l|l|}
\hline $\begin{array}{l}\text { Main factor effective on the selection of informal settlements as the } \\
\text { residence }\end{array}$ & Karganeh & Ali Abad & Gel Sefid \\
\hline Low rentals for properties & 40.1 & 35.6 & 51.2 \\
\hline The presence of ethnics, citizens and members of the same tribe & 23.3 & 14.8 & 18.4 \\
\hline $\begin{array}{l}\text { The existence of appropriate accesses to facilitate the access to } \\
\text { workplace, education, entertainment and family purchase }\end{array}$ & 10.4 & 11.4 & 5.9 \\
\hline High possibility of findings jobs for oneself and family members & 1.2 & 5.1 & 8.7 \\
\hline The possibility of utilizing free in charge from consuming splits & 3.2 & 5.4 & 5.3 \\
\hline Anonymity and farness form tumult of cities & 6.8 & 7.4 & 2.6 \\
\hline
\end{tabular}




\begin{tabular}{|l|l|l|l|l|}
\hline $\begin{array}{c}\text { Appropriate landscape and desirability of natural features of } \\
\text { neighborhood }\end{array}$ & 12.8 & 14.2 & 5.3 \\
\hline Others & 2.2 & 6.1 & 2.6 \\
\hline Total & 100 & 100 & 100 \\
\hline
\end{tabular}

The results of the above figures indicate that the most important and main factor in paying attention to the rural immigrants to select the informal settlements as the most appropriate place for residence, low rentals for properties of these neighborhoods which this issue have been investigated both in primary formation and construction and as a factor effective on the continuance of the attention to it during next years.

The high proportion of this factor in the neighborhood Gel Sefid, in comparison with two other neighborhoods can confirm this issue that first, due to the inappropriate physical structure and high slope of this neighborhood and also being in the line of natural threats such as seasonal floods and falling mountain rocks, this informal settlement have the least spatial value in comparison with the two other ones, and secondly the existence of such conditions can naturally attract that part of the immigrants who are less affluent than other immigrants to this settlement and engender a kind of pull and natural leading to sieve the poorer immigrants toward this neighborhood.

The second motivational factor which has a significant proportion in selecting all three informal settlement as the target regions of rural immigrants is the existence of relatives and people of the same village who previously seized or purchased this neighborhoods as their residences successfully and with the least costs. Awareness of the situation of these individuals will be disseminated rapidly among the relatives and this issue promote the motivation of the residents to displace and migrate to the same settlement.

The importance of other motivational factors for the neighborhoods are different to some extent. Informal settlements of Ali Abad and Karganeh, due to being close to each other and also to the beautiful hillsides and having natural attractions such as rivers and untapped heights, have the next proportion among the motivational factors to attract rural immigrants to the city. This is while due to the reasons mentioned, Gel Sefid settlement lacks these attractions and this issue is reflected in statistical tables well.

On the other hand, neighboring of Gel Sefid neighborhood with city's cemetery and being located on the path of access to the west of Khorramabad, the possibility of finding jobs particularly false jobs such as selling water for washing graves, proving the materials for constructing graves such as lime and sand, selling flowers, rose water and dates particularly in Thursdays (the day for meeting graves) to the visitors and also providing and selling foods, drinks and refreshments to the travelers of the western regions of Khorramabad, the place of the factor of job for the residents of this neighborhood increases in comparison with the two other neighborhoods and this factor and promotes to the third rank.

\subsection{Rural Repulsion Factors}

Successive droughts, the crisis of the shortage of drink water, prevalence of contagious and deadly diseases, the outbreaks of pests and diseases, natural disasters such as earthquakes, fires, 
landslides, floods and famine, local conflicts and quarrel, political events such as war and revolution, industrial events such as chemical and nuclear explosions are among the rural repulsion factors which are considered as a considerable parts of the reasons for villagers immigrations.

The data obtained from the statistical questionnaires identify the proportion of the group of "rural repulsion" factors in the immigration of the villagers who select the informal settlements of Khorramabad as their residence for the studied three regions as follows.

\begin{tabular}{|l|l|l|l|}
\hline Group of motivational factors & Karganeh & Ali Abad & Gel Sefid \\
\hline Rural repulsion factors & 58.7 & 52.8 & 59.2 \\
\hline
\end{tabular}

The comparison of the role of "rural repulsion" factors with the "urban attraction" ones in migrating the villagers' immigrations to Khorramabad indicates the more effective role of rural repulsion factors in this regard which this relative superiority can be observable among the rural immigrants of three neighborhoods.

In overviewing, the existence of many of the challenges and repulsion factors such as the occurrence of coercive disasters, especially floods and lightning, the prevalence of ruinous and fatal diseases such as smallpox, measles and malaria, reducing the share of small owners due to the accomplishment of the project of land reform and inheritance laws, The occurrence of sectarian conflicts and strife and etc. is observable and therefore, these factors pave the path for creating many challenges particularly economic ones for rural residents in that period of time; therefore, these reasons are the elements of the outnumbering the proportion of the urban attractions to rural repulsion factors.

\section{The Situation of Forming Informal Settlements in the City and Its Population Diversity and Composition}

The results of the conducted results confirm the relationship between the rural immigrations and the situation of formation of the informal settlements in Khorramabad. Principally, a significant correlation between the paths of the arrival of immigrants to the cities with settled situation and the place of the immigrants. It means that principally, rural immigrants, due to unfamiliarity with other urban neighborhoods and also the feasibility of transportation between previous rural settlement and the current settlement and also easier access of the rural relatives to the new place, severely tend to settle close to the gate and points of entry to the city. This issue regarding the war immigrants and also the immigrants of other cities to the host cities.

Population composition of Khorramabad consists of different tribes and clans. Now, a significant part of the population of the city is consist of tribes and nomads each of which, according to its social situation, financial affluence and also the composition of population context lives in neighborhoods of the city.

In the following table, the tribal composition, dispersion and the diversity of the residents of the studied informal settlement are presented.

\begin{tabular}{|l|l|l|l|}
\hline Tribal Composition & Karganeh & Ali Abad & Gel Sefid \\
\hline Beiranvand & 72.3 & 20.7 & - \\
\hline Chegeni & 1.7 & 6.6 & 53.8 \\
\hline
\end{tabular}




\begin{tabular}{|l|l|l|l|}
\hline Balagariveh & 1.7 & 9.4 & 3.8 \\
\hline Hassanvand & 5 & 3.8 & 11.5 \\
\hline Others & 19.3 & 59.5 & 30.9 \\
\hline Total & 100 & 100 & 100 \\
\hline
\end{tabular}

The comparison of this table with the geographical situation of the nomads residing in villages around Khorramabad identifies the relationship between the population compositions of studied informal settlements with the spatial situation of these villages. With an overview to the dispersion of the villages resided by Beyranvand tribe in the geographical map which are mainly located in the east of the city and by considering the situation of formation of informal settlement of Kerganeh in the eastern entrance path of Khorramabad and its comparison with the population composition dependent ton this tribe with the amount of $72 \%$, we can find the significant correlation between the formation of informal settlements and the immigrants' entrance path of to the city. The same issue can be well observable for Gel Sefid which is located in the eastern entrance path of Khorramabad.

The high proportion of the residents of Chegini tribe with the amount of $53.8 \%$ in this settlement and the main dispersion and establishment of the villages of this tribe in the western area of the city of Khorramabad is another confirmation of this claim. The confirmation and analysis of this issue for informal settlement Ali Abad is somehow more complicated and different. However the spatial situation of this settlement in the west of Khorrambad makes the highness of population composition of the residents of this settlement as expected in the benefit of Beyranvand, with a view to the extracted figures in the above table and in spite of the fact that the proportion of the residents of this tribe from the total population composition is considerable (20.7). But the main issue is the significance of the proportion of the other tribes and the high tribal diversity in this neighborhood, which leads us to this reality that over time and the high oldness of the formation of informal settlements, the population composition of these neighborhoods due to the continuance of displacements and the continuation of the population flows in them gradually is changed and its population gradually is more diverse and heterogeneous.

\section{Investigating the Probability of Displacement and Immigration of the Residents of the Informal Settlements in the Connected Network of Iran's Settlements}

Nowadays, with the increasing population growth in the world's great metropolises, a lot of urban issues and insufficiencies such as traffic, air pollution, marginalization and different kinds of social crimes have covered the city, which has foreclosed the conditions for creation of an ideal life in a clean, secure, beautiful and affluent city for its residents. Experts believe that due to the domination of the above conditions, the urban system and network of Iran enter the third period of the evolution stages in the urban systems in such a way that in metropolitan areas, with the objective of creating balance in this network, the phenomenon of city aversion or urban divergence is occurring (Nazarian, 2009: 205) and a kind of reverse immigration from the metropolises to small cities, countryside and villages is shaped which can engenders the ground of the gradual decrease of the population in these cities.

To know the process of immigrant-permitting of the future of the capital and big cities and 
investigate the effects due to the immigration flows form small and medium cities and villages which in general consist of some part of the connected settlement network and be informed of this issue whether the phenomenon of reverse immigration in Khorramabad and particularly in the scope of informal settlements of this city are expectable in the future, there are some comprehensive survey studies which the results of some of them are as follows:

\begin{tabular}{|l|l|l|l|}
\hline The issue by which the residents of the informal settlements are questioned & Karganeh & Ali Abad & Gel Sefid \\
\hline Tending to migrate to Tehran & 56.4 & 38.5 & 77 \\
\hline Tending to migrate to a big and industrial city & 48.4 & 34.4 & 52 \\
\hline Tending to migrate to a smaller town & 12.8 & 8.4 & 20 \\
\hline Tending to migrate to a village & 9.5 & 6.9 & 16.7 \\
\hline
\end{tabular}

The results obtained from the present research indicate that a sensible and significant tendency is present among the residents of this settlements to migrate to Tehran. A large part of the respondents, during answering this question, because Khorramabad could not satisfy their expectations regarding appropriate employment and housing, they were disappointed with living in their neighborhoods and pursued an opportunity to migrate to this city.

They believe that because they have left their villages and migrate to other place, then it is better that they should live in a city which they at least can play a positive role regarding providing employment and consequently promoting the life state and economic aspects of their families. What is considerable in this research is that the amount of the tendency of the residents of informal settlement to migrate from the current place to a city or center of other settlements decreases as the area and population of the new town or the center and reduce. It means that the tendency to migrate to the capital in the highest level of tendency and migrate to other population centers, i.e. a big city, a small city and a village gradually decreases.

Another considerable issue is which the results of the study confirm is that however a little population of the residents of the capital or metropolises of Iran, in line with the evolution of urban systems, started a kind of reverse migration, due to the insignificant rate of this kind of migration compared to the process of immigrant-permitting of these cities, there is no practically positive effect on decreasing their population and it seems that with the continuance of this process for future years, we will observe even more population-permitting of big cities and consequently a lot of negative outcomes of overcrowding such as marginalization and formation of new informal settlement. Another significant result is that a lot of the residents of this settlements even in case of supplying appropriate conditions in previous villages, because of the negative mental background, they have no tendency or desire to return and if this theory can be generalizable to other levels and the residents of other cities, it can be hypothesized that in the future, the process of decreasing rural population will continue and additionally, the proportion of rural population compared to the total population of the country decrease gradually and the number of non-residents villages in Iran will increase.

\section{Conclusion}

Every geographical space is an independent locational-spatial system which in spite of its independce is considered as a sub-system of higher systems which are constructed influenced by other factors and elements and the flows and processes available in them can create 
considerable changes in the whole system.

Informal settlements as part of the corpus of Khoramabad, on the one hand is influenced by the existence and establishment of an uneven immigration process and on the other hand, have been constructed due to imbalance between the supply and demand of housing in formal markets. Experts consider the factors of formation of village-to-city immigrations as the most considerable type of migrations to Khorramabad and divide it into two main groups of push (repulsion) factors and pull (attraction) ones.

The results of the present study indicate the relative superiority of the role of rural repulsion factors over urban attraction factors in the formation of immigrations. Although it may be imagined that due to the existence of a lot of desirable conditions the possibility of creation of an appropriate life exists in the villages of the province for now, with a more attentive view to the time period of the formation of informal settlements which mainly refers to 50 years ago, we can find out the existence of a lot of limitations and repulsion factors such as natural factors, conflicts and inefficient sites which result in the decrease in rural smallholders' proportion.

Other results of the study indicate that there is a significant correlation between the path and the arrival of rural immigrants to the city and the situation of the formation of informal settlements. Rural immigrants, due to different reasons including easier access and transportation between villages and current settlements and also unfamiliarity with other urban points, tend eagerly to reside in their path and gateway of arrival to the city.

The obtained results confirm the existence of a significant correlation between the composition and frequency of the population of the residents of informal settlements and clans and tribes residing in villages located in their paths. It means that more than $50 \%$ of the residents of the informal settlements are the rural immigrants of the tribes residing in the same path and geographical situation.

In the analysis of this research the existence of a sensible and considerable tendency among the residents of these settlements to migrate to the center and other big cities can be observed. A lot of the residents, due to dissatisfaction with their occupational and income situations, tend to migrate to bigger cities, which the amount of this tendency gradually decreases as the target city become smaller.

It seems that the settlement network of Iran as a connected network and influenced by each other, influenced by the immigration flows will change considerably in the future and in addition to the fact that the proportion of rural population compared to the total population of the country is decreasing continuously, the number of the non-resident villages increasingly adds. As a result, in the future, we can observe the formation of new informal settlements, particularly in big cities influenced by these processes. Surely, these cities, because of extensive population-permitting will encounter the phenomenon of the population explosion and formation of a lot of urban insufficiencies.

\section{References}

Eftekhari, Z. (2003). Representation of the textures of informal settlement and the factors 


\section{Macrothink}

Environmental Management and Sustainable Development

ISSN 2164-7682

2014, Vol. 3, No. 2

effective on its formation, the proceedings of the conference on marginalization and informal settlement. Vol. 1. Tehran: University Press of Welfare and Rehabilitation Sciences, pp. 59-80.

Shokuee, H. (2010). Social geography of cities. Jihad Daneshgahi publication.

Jamali, F. (2002). Immigration, cities and immigrants' compatibility. Journal of Human Sciences Faculty, University of Tabriz. 182, 61-81.

Haj Yousofi, A. (2003). The phenomenon of marginalization before the Revolution. , the proceedings of the conference on marginalization and informal settlement. Vol. 1. Tehran: University Press of Welfare and Rehabilitation Sciences, pp. 177-206.

Zahed Zahedani, S. (1990). Marginalization. Shiraz: Shiraz University Press.

Samavati, M. E. (1993). Categories of social problems in Hamadan province. Hamedan Governorate. Social council of Hamedan.

Nazarian, A. (2009). The dynamics of Iran's urban system. Mobtakeran publication.

Naghdi, A. (2003). An introduction to urban sociology. Hamedan. Fanavaran publication.

Varesi, H. \& Sarvari, Z. (2006). An analysis on the relations of development, immigration and urbanization. Journal of Geography and Regional Development, 65, 196-180.

Gizewsky - Thomas (1996), "urban growth and violence", on ILO 1995.

UN-HABITAT (2003), challenge of Slums: Global report on Human Settlement.

\section{Copyright Disclaimer}

Copyright for this article is retained by the author(s), with first publication rights granted to the journal.

This is an open-access article distributed under the terms and conditions of the Creative Commons Attribution license (http://creativecommons.org/licenses/by/3.0/). 